\title{
Trends of parallel microstructure and magnetic properties evolution in Co0.5Zn0.5Fe2O4
}

\begin{abstract}
The present paper reports on an effort to expose and scientifically explain the microstructureï magnetic properties relationship as they evolve with increasing sintering temperature. Mechanical alloying was used to prepare cobaltï zinc ferrite nanoparticles with sintering temperature from 800 to $1,350{ }^{\circ} \mathrm{C}$ with $50{ }^{\circ} \mathrm{C}$ increment. The microstructure of the samples was observed using a field emission scanning electron microscope, and the magnetic parameters, such as the real permeability and loss factor, were measured at room temperature in the frequency range from $10 \mathrm{MHz}$ to $1.0 \mathrm{GHz}$ using an Agilent 4291B impedance/material analyzer. The Bï H hysteresis of the samples was investigated using a MATS-2010SD Static Hysteresisgraph. From the results, the real permeability and loss factor were observed to increase up to $1,250{ }^{\circ} \mathrm{C}$. These increases corresponded to increases in grain size and are mainly due to easier domain wall movement. However, due to zinc loss, عNind ع the saturation induction decreased from 1,300 to $1,350{ }^{\circ} \mathrm{C}$. The coercivity increased up to 850 ${ }^{\circ} \mathrm{C}$ and decreased with increasing temperature. This increasing-to-decreasing coercivity trend corresponded well with the single- to multi-domain grain size transition marked by critical grain size at about $0.13 \mathrm{\varepsilon m}$.
\end{abstract}

Keyword: Magnetic properties; Microstructure; Mechanical alloying; Spinel 